http://ejournal.upi.edu/index.php/jaz - e-mail: jurnal.zonasi@gmail.com dan jurnal_zonasi@upi.edu doi.org/10.17509/jaz.v3i2.24448

\title{
KAJIAN KONSEP BIOPHILIC PADA BANGUNAN HUNIAN VERTIKAL
}

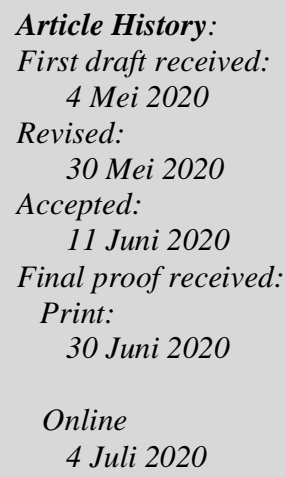

Jurnal Arsitektur ZONASI is indexed and listed in several databases:

SINTA 4 (Arjuna)

GARUDA (Garda Rujukan Digital)

Google Scholar

Dimensions

oneSearch

BASE

Member:
Crossref
RJI
APTARI
FJA (Forum Jurna Arsitektur)
IAI
AJPKM

\author{
Diana Azkiawati ${ }^{1}$ \\ Finta Lissimia $^{2}$ \\ 1,2 Universitas Muhammadiyah Jakarta \\ Jalan Cempaka Putih Tengah 27 No.27 Cempaka Putih, Jakarta Pusat \\ Email: dianaawt@gmail.com \\ Finta.lissimia@ftumj.ac.id
}

\begin{abstract}
The concept of biophilic is a concept that pays attention to the relationship between natural surrounding with user's psychology. The application of the biophilic concept is expected to create a condition or atmosphere where people do not feel stressed and reduce one's stress level. The advantage of applying the biophilic concept to a residence is to create a healthier condition for people who are mentally healthy. Therefore, the authors raise a study entitled "Biophilic Concept Studies in Vertical Residential Buildings". This research was conducted in studies namely, Kollektiv Hotel, Bandung by using descriptive analysis by emphasizing the facts or the truth of the data obtained. The method in this study uses a descriptive approach that is to reveal the situation or situation that occurs when the research is ongoing. Based on observations made, it is known that biophilic architecture can be applied by connecting natural elements with their usage.
\end{abstract}

Keywords: Biophilic concept, occupancy, user's psychology

\begin{abstract}
Abstrak: Konsep biophilic merupakan konsep yang memperhatikan hubungan antara alam sekitar dengan psikologis pengguna Penerapan konsep biophilic diharap dapat menciptakan kondisi atau suasana dimana masyarakat tidak merasa stress serta mengurangi tingkat kestresan seseorang. Keuntungan menerapkan konsep biophilic terhadap hunian adalah menciptakan kondisi masyarakat yang lebih sehat secara mental Oleh karena itu, penulis mengangkat penelitian yang berjudul "Kajian Konsep Biophilic Pada Bangunan Hunian Vertikal". Penelitian ini dilakukan pada studi kasus yaitu, Kollektiv Hotel, Bandung menggunakan analisis deskriptif dengan menekankan fakta atau kebenaran data yang didapat. Metode pada penelitian ini menggunakan metode pendekatan deskriptif yaitu mengungkapkan keadaan atau situasi yang terjadi saat penelitian sedang berlangsung. Berdasarkan observasi yang dilakukan, diketahui bahwa arsitektur biophilic dapat diterapkan dengan menghubungkan elemen-elemen alam dengan penggunannya.

Kata Kunci: Konsep biophilic, Hunian, Psikologis Pengguna
\end{abstract}

\section{Pendahuluan}

Penuruanan jumlah populasi penduduk yang tinggal di daerah pedesaan, serta terjadinya peningkatan jumlah penduduk di daerah perkotaan. Pertumbahan dan perkembangan di daerah perkotaan sangat mempengaruhi kinerja dari pusat kota. Peningkatan jumalah peduduk di pusat kota menyebabkan pemanfaatan lahan di Kota Jakarta menjadi terbatas. Lahan yang terbatas akan berdampak pada harga jual lahan yang semakin mahal.

Isu permasalahan tentang keterbatasan lahan di Jakarta, dapat dicegah dengan penggusuran atau relokasi penduduk lama ke tempat yang baru mengarah pada pembangunan hunian vertikal. Perencanaan dan perancangan sebuah bangunan perlu adanya konsep arsitektur baru, dengan mengedepankan dan perduli terhadap isu kelestarian lingkungan serta psikologis masyarakat sekitar. Berdasarkan pemaparan diatas, dirasa perlu mengkaji tentang perencanaan pembangunan dengan menggunakan konsep biophilic. Konsep biophilic merupakan konsep yang memperhatikan hubungan antar alam sekitar dengan psikologis pengguna.

Teori yang digunakan mencakup teori dan prinsip konsep biophilic dan konsep tentang bangunan vertikal. Tujuan penelitian ini untuk mengkaji konsep biophilic pada bangunan hunian vertikal. 


\section{Metode Penelitian}

Penelitian ini menggunakan pendekatan secara deskriptif kualitatif. Pendekatan deskriptif digunakan dengan tujuan mengungkap keadaan atau situasi yang terjadi saat penelitian sedang berlangsung. Sedangkan analisis kualitatif digunakan sebagai pertimbangan memandang fakta atau kebenaran data. Sehingga metode deskriptif kualitatif dipilih dalam penelitian ini karena terdapat hal-hal kompleks yang tidak hanya dijelaskan oleh angka melaikan tentang pendekatan perasaan maupun emosional antara peneliti dan responden sehingga menghasilkan data yang mendalam.

Hunian vertikal yang dijadikan studi kasus adalah Kollektiv Hotel, Bandung. Pemilihan studi kasus dalam penelitian ini dilakukan dengan pendekatan penelitian naturalistik. Menurut Guba dan Lincoln (1985) naturalistik merupakan sebuah objek yang diteliti secara langsung bersifat apa adanya.

Berkaitan dengan pemilihan metode pendekatan ini, agar sesuai dengan tujuan penelitian maka ada beberapa kriteria yang ditetapkan. Pertama, merupakan bangunan residensial yang berhubungan dengan alam. Kedua, merupakan bangunan residensial yang menggabungkan unsur-unsur alami, seperti: pencahayaan alami, pemandangan luar, bukaan, tumbuhan dan tanaman hijau. Ketiga, Bangunan residensial yang menggunakan material alami. Keempat, mengandung pola dalam konsep biophilic yang harus diimplementasikan pada bangunan.

\section{Hasil dan Pembahasan}

\subsection{Data Fisik Bangunan}

\section{- Deskripsi Bangunan}

Nama Bangunan

Lokasi

Tipologi

Dibangun

Kellektiv Hotel merupakan hotel pertama di Bandung yang dibangun dengan Container. Bangun yang berasal dari peti kemas ini dirancang ulang dengan menggabungkan unsur tanaman rambat pada sekitaran void dan terdapat pohonan yang besar yang menjulang keatas, penggunaan material kayu, serta mengangkat tema industrialis. Dengan penggabungan tema dan material pada hotel ini, pengunjung dapat merasakan ketenangan dan kenyamanan.

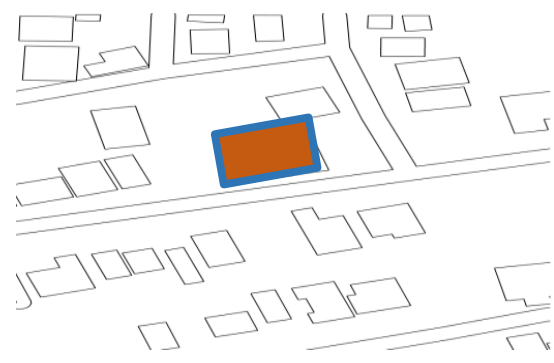

Gambar 1. Lokasi Kollektiv Hotel

Sumber: Cadmapper, 2019

Aspek fisik yang diperoleh dari bangunan Kollektive Hotel ini meliputi beberapa fasilitas penunjang hotel dan penggunaan materialnya serta dikelilingi oleh pepohonan rambat berwarna hijau yang lebat, sehingga dapat membuat pengunjung merasakan kenyamanan dan ketenangan.

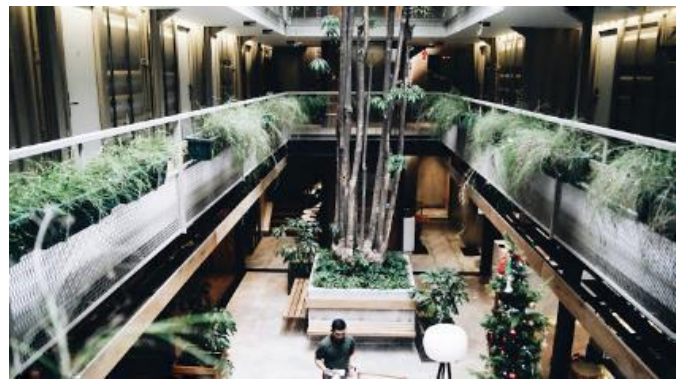

Gambar 2. Eksisting Kollektiv Hotel

Sumber: Data peneliti, 2019

Pada bagian lobby terdapat bukaan pada atap yang berfungsi untuk pencahayaan dan penghawaan alami serta untuk mengurangi penggunaan cahaya buatan. Adanya bukaan berbentuk 
vertikal pada dinding berfungsi sebagai keluar masuknya cahaya maupun udara alami sehingga dapat meminimalisir penggunaan cahaya buatan dan penghawaan buatan. Pohonan menjulang tinggi yang berada ditengah-tengah lobby dengan perpaduan bukaan untuk cahaya memberi rasa seolah sedang berada di alam lepas.

Selain itu terdapat burung dalam sangkar di setiap sudut kanan mau pun kiri sehingga menghasilkan suara kicauan burung yang merdu membawa pengunjung seolah sedang berada di alam. Tanaman di dalam ruangan yang menggunakan media pot maupun langsung ke tanah, serta adanya bebatuan kecil membentuk sebuah aroma khas yang sangat alami. Layout bangunan dibuat mengelilingi void yang besar untuk menjamin sirkulasi udara dan pencahayaan alami.

\section{- Denah}

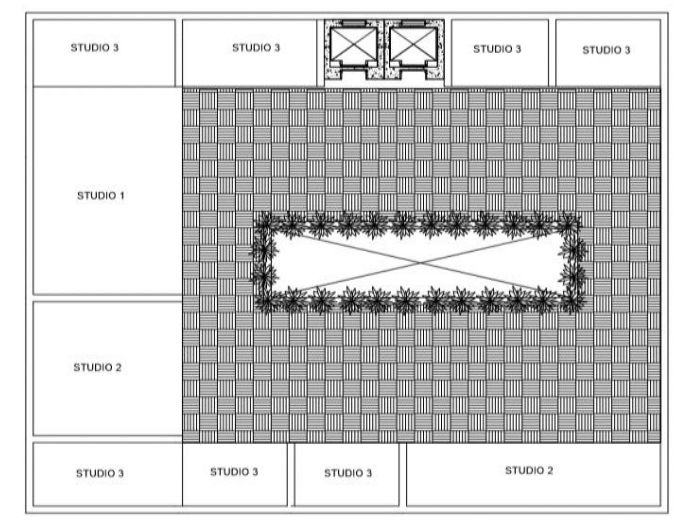

Gambar 3. Denah Kollektiv Hotel

Sumber: Data penulis, 2019

Layout bangunan dibuat secara berulang dan teratur atau pembuatan denah dilakukan dengan bentuk atau pola yang sama, hal ini dikarenakan penggunaan bentuk ini terlihat lebih simetris serta dapat memberikan efek psikologis yang positif bagi penggunanya.mengelilingi void yang besar untuk menjami sirkulasi udara dan pencahayaan alami. Bangunan di buat berjarak dengan tembok pagar agar meminimalisir gangguan terhadap tetangga yang bersinggunggan/berdekatan, ini juga untuk menjamin semua ruang mendapatkan cross ventilation. Ketinggian level dasar bangunan ditentukan berdasarkan keinginan untuk tidak membuang tanah galian keluar site. Air limbah dilakukan filterisasi dikelola dalam site digunakan untuk penyiraman tanaman. Selain itu dilakukan pengelolaan energi listrik secara efisien dan optimal (memanfaatkan energi gravitasi untuk distribusi air secara vertikal, mengurangi/menurunkan spesifikasi beberapa pemakaian alat elektonik dalam interior kamar hotel seperti refrigenerator dan AC). Selain itu secara umum material yang digunakan dalam bangunan ini (eksterior dan interior) di upayakan secara optimal memanfaatkan material reuse, recycle, reduce juga material reject.

\subsection{Implementasi Desain Biophilic pada Bangunan}

\subsubsection{Nature in The Space}

\section{- Visual Connection with Nature}

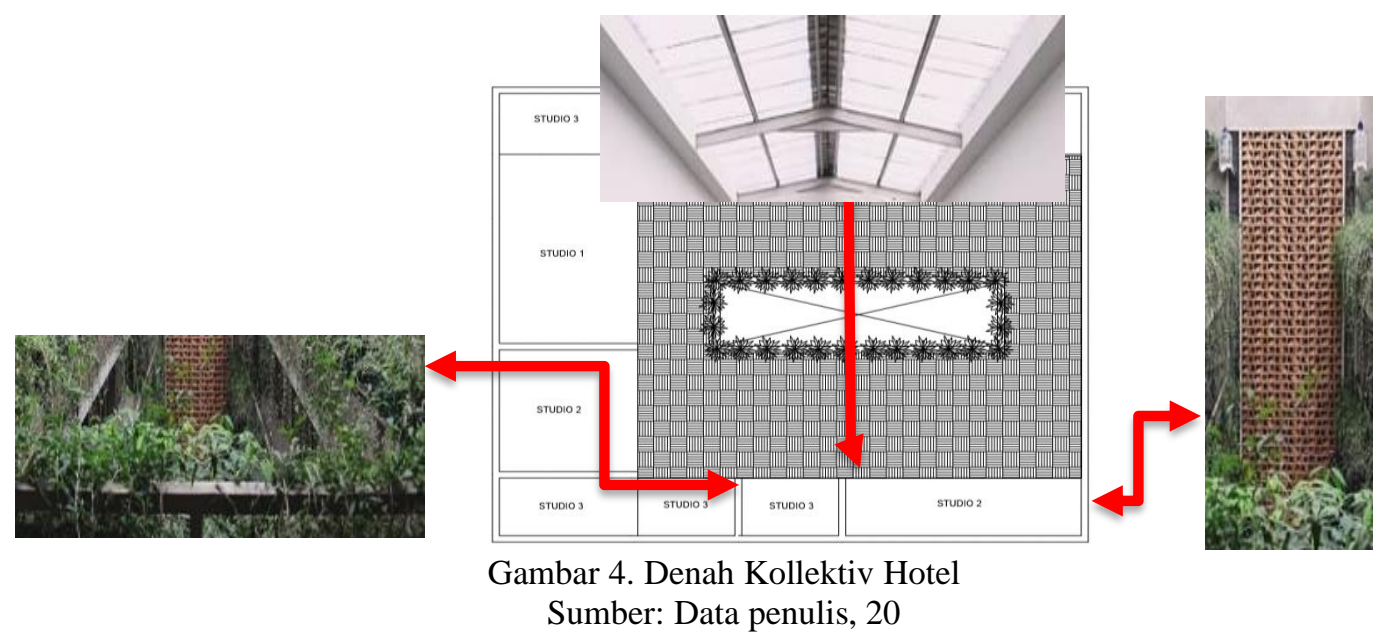


Naturally Occurring yang terdapat di Kollektiv Hotel yaitu adanya bukaan pada atap yang berfungsi sebagai keluar masuknya cahaya mau pun udara alami sehingga dapat meminimalisir penggunaan cahaya buatan. Adanya bukaan berbentuk adanya bukaan berbentuk vertikal pada dinding berfungsi sebagai keluar masuknya cahaya maupun udara alami sehingga dapat meminimalisir penggunaan cahaya buatan dan penghawaan buatan.

Simulated nature yang terdapat pada hotel ini yaitu penggunaan pepohonan yang menurut teori iklim makro dan mikro berfungsi sebagai pengaruh terhadap suhu ruangan di dalamnya sehingga pengguna merasakan nyaman.

\section{- Non-Visual Connection with Nature}

\section{Sound (Suara)}

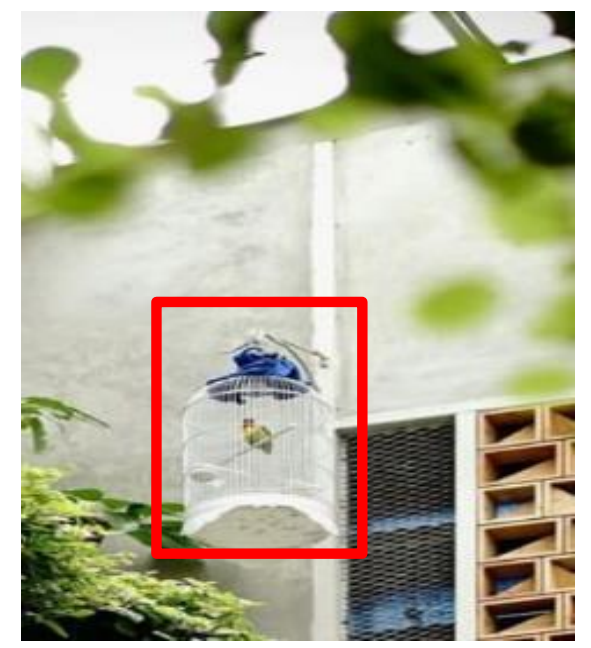

Gambar 5. Kollektiv Hotel

Sumber: Data penulis, 2019

Terdapat burung dalam sangkar pada sudut atas kanan dan kiri lobby. Sehingga menghasilkan suara kicauan burung yang merdu membawa pengunjung seolah sedang berada di alam. Suara kicauan burung dapat menghilangkan kejenuhan sehingga dapat menenangkan pikiran dan perasaan pengunjung.

\section{Touch (Sentuhan)}

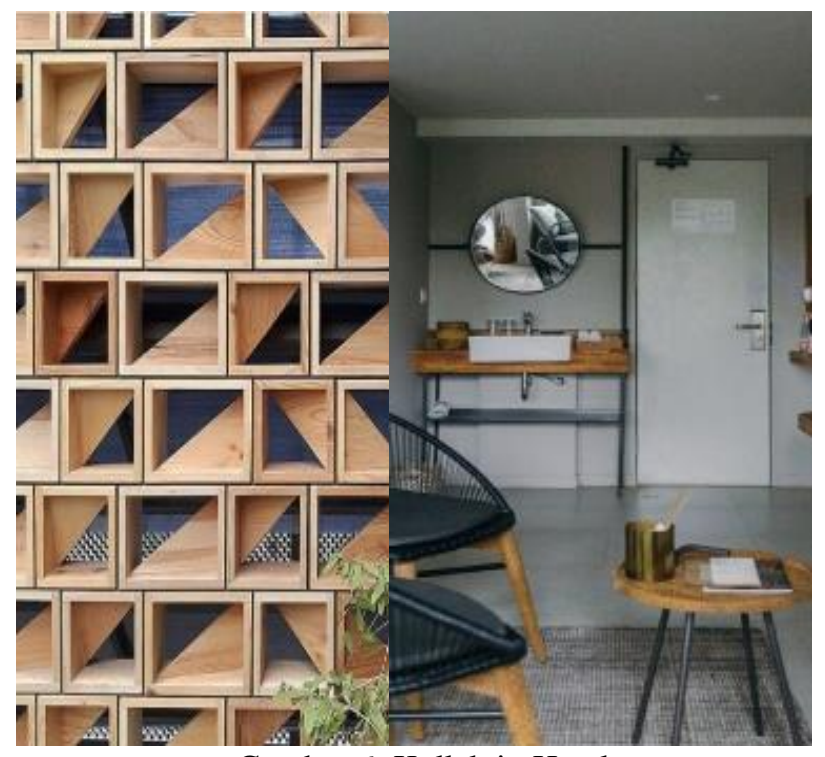

Gambar 6. Kollektiv Hotel

Sumber: Data penulis, 2019

Material yang dominan digunakan adalah material kayu. Selain itu tampilan abu-abu serta interior yang seolah tidak difinishing memberikan sentuhan alami.Material interior yang digunakan yaitu dengan memanfaatkan material berasal dari reuse, recycle, reduce. Penggunaan material tersebut berasal dari material 
alam agar penggunaan bahan dasar alam lebih efisien serta mengurangi penggunaan material yang berpotensi merusak alam.

3. Scent (Aroma)

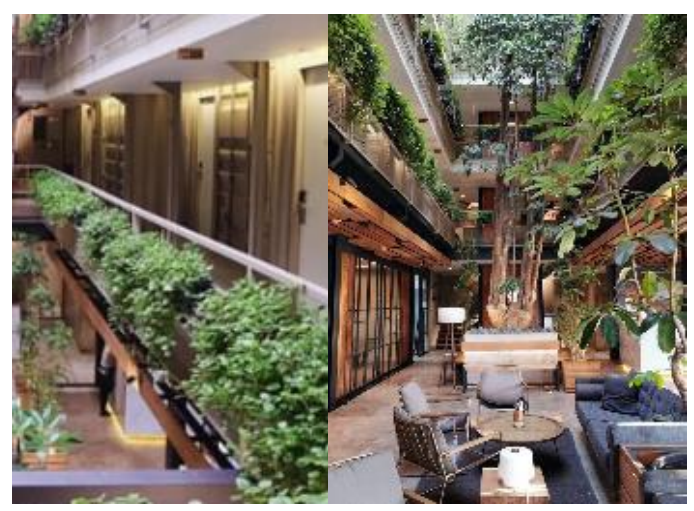

Gambar 7. Kollektiv Hotel

Sumber: Data penulis, 2019

Tanaman di dalam ruangan yang menggunakan media pot maupun langsung ke tanah, serta adanya bebatuan kecil membentuk sebuah aroma khas yang sangat alami.

4. Taste (Rasa)

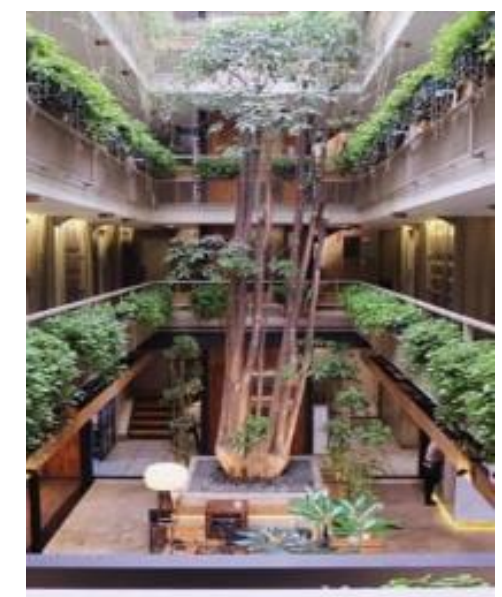

Gambar 8. Kollektiv Hotel

Sumber: Data penulis, 2019

Pohonan menjulang tinggi yang berada ditengah-tengah lobby dengan perpaduan bukaan untuk cahaya memberi rasa seolah sedang berada di alam lepas dan membuat pengunjung merileksasikan pikiran.

\section{- Non-Rhythmic Sensory Stimuli}

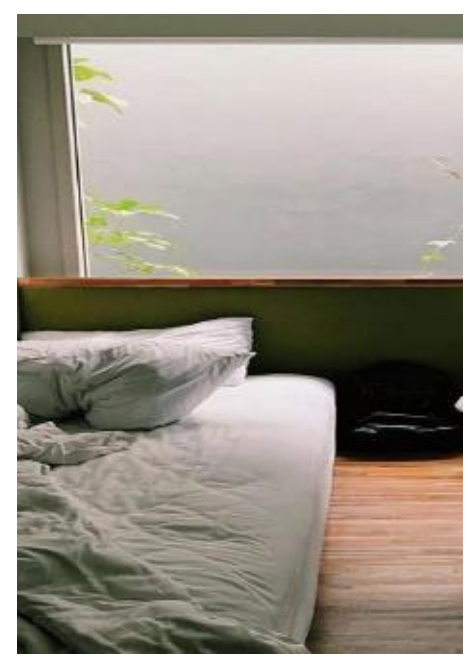

Gambar 9. Kollektiv Hotel

Sumber: Data penulis, 2019 
Matahari pagi dan tanaman hijau yang mengintip dari jendelakamar hotel, serta perpaduan warna material kayu berwarna coklat meberi kesan monokrom sehingga membuat seseorang berhenti dari aktivitasnya dan memilih menikmati pemandangan tersebut agar lebih rilex.

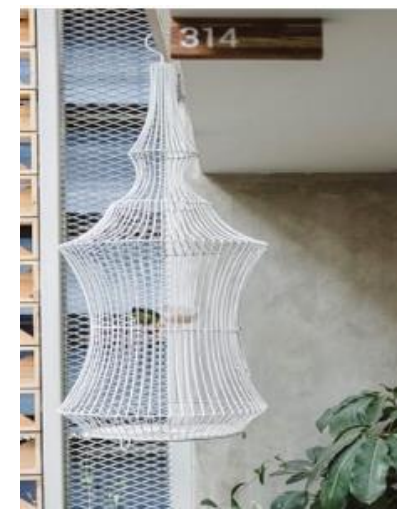

Gambar 10. Kollektiv Hotel

Sumber: Pribadi, 2019

Suara yang berkicau dipadukan dengan bayangan yang dibentuk dari pembiasan matahari, memberi kesan seperti berada di alam bebas, sehingga membuat pengunjung merasa nyaman dan lebih rilex.

\section{- Thermal \& Airflow Variability}

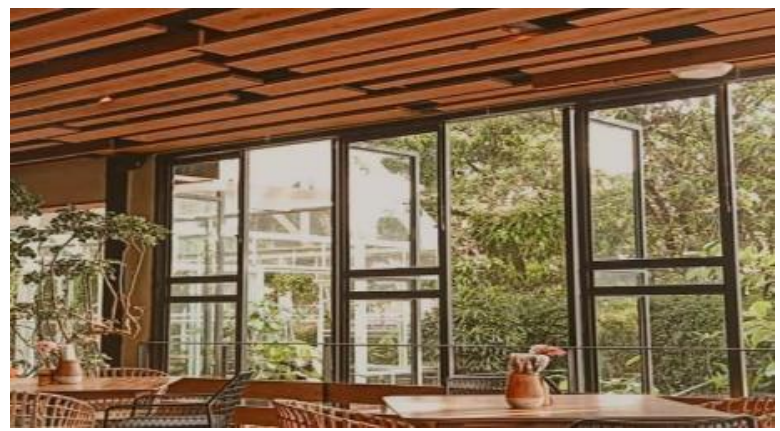

Gambar 11. Kollektiv Hotel

Sumber: Data penulis, 2019

Penempatan bukaan serta ukuran bukaan dengan menggunakan partisi kaca membuat pemandangan dari luar terekspose. Sekeliling bukaan jadi kenyamanan termal dibantu oleh pepohonan dan angin yang masuk difilter oleh pepohonan, sehingga menimbulkan penghawaan yang nyaman kombinasi dari unsur -unsur tersebut menimbulkan ruang yang nyaman tanpa penghawaan buatan.

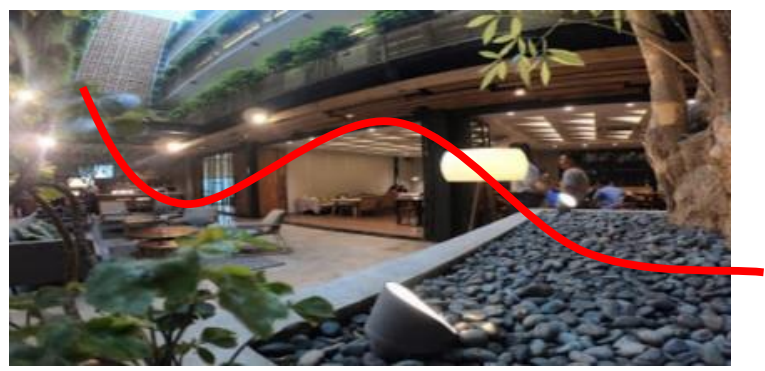

Gambar 12. Kollektiv Hotel

Sumber: Data penulis, 2019

Bangunan dibuat mengelilingi void yang besar untuk menjamin sirkulasi udara dan pencahayaan alami. Terdapat bukaan besar berbentuk vertical untuk menjamin semua ruang mendapat cross ventilation berupa penghawaan maupun pencahayaan alami yang baik. 


\section{- Connection with Natural Systems}

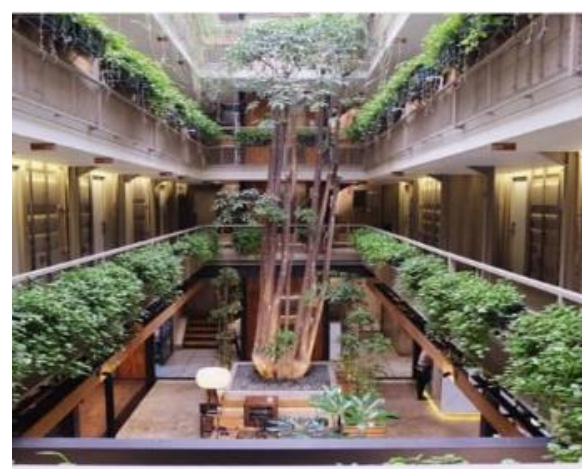

Gambar 13. Kollektiv Hotel

Sumber: Data penulis, 2019

Salah satu solusi terbaik untuk memasukkan cahaya alami serta udara ke dalam rumah selain menggunakan jendela adalah dengan membuat bukaan pada atap atau biasa disebut skylight. Skylight terletak di langit-langit sehingga aplikasinya lebih efektif untuk menerangi ruangan sehingga dapat meminimalisir penggunaan pencahayaan buatan. Karena berfungsi sebagai bukaan, maka material yang umumnya digunakan berupa material transparan seperti fiber, polycarbonat atau kaca maupun bahan yang ringan namun tetap kuat untuk mengurangi risiko keretakan.

\subsubsection{Nature Analogues}

\section{- Material Connection to Nature}

Tabel 1. Penggunaan Material Alami pada Kollektiv Hotel

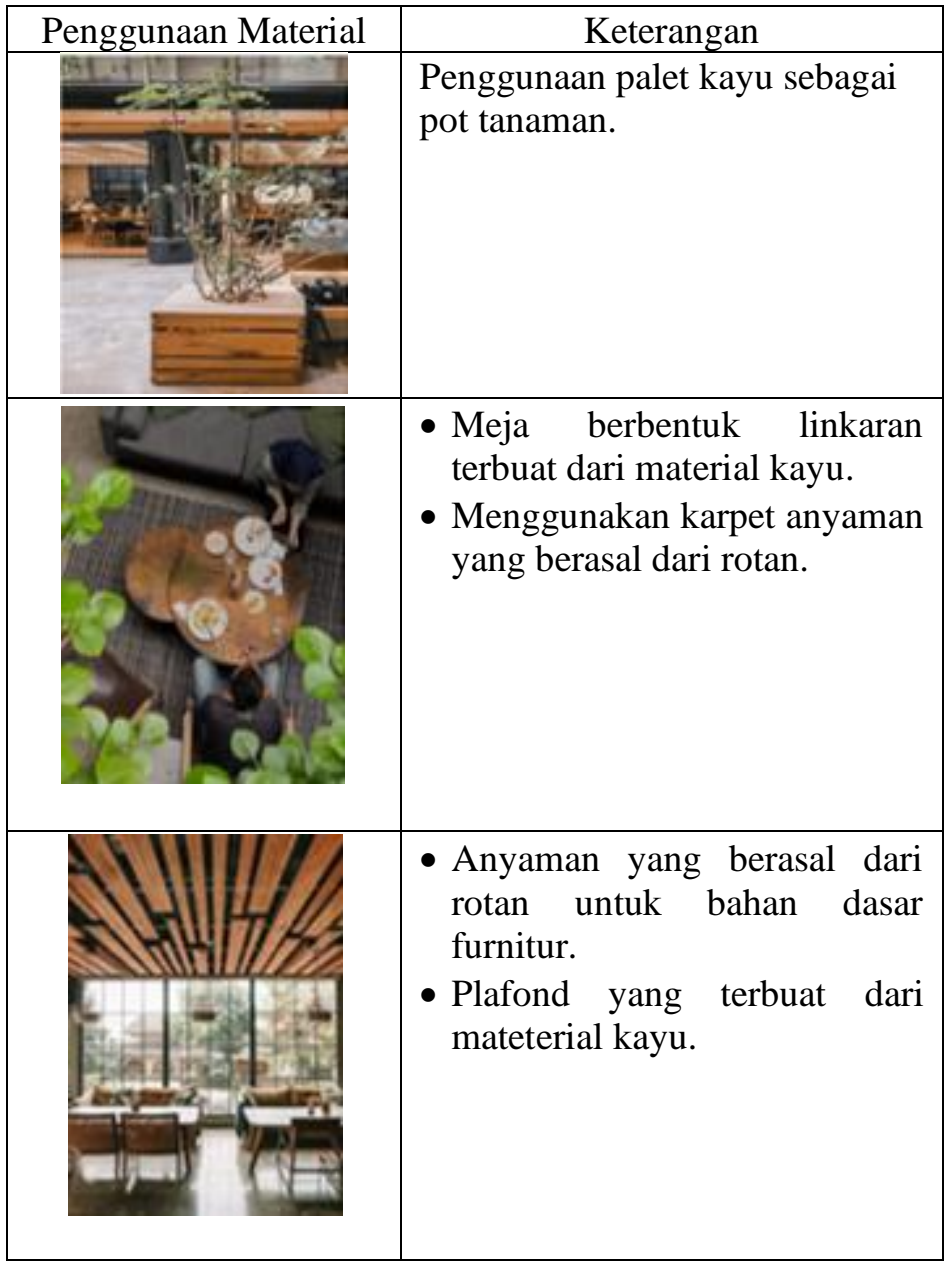




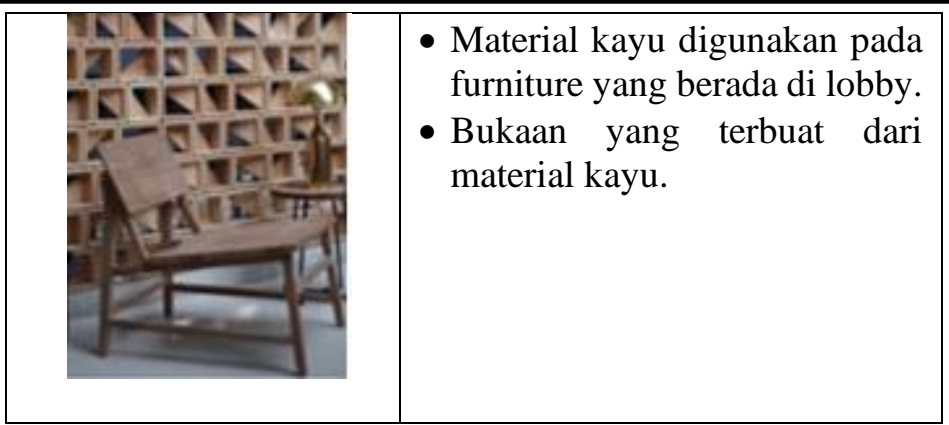

(Sumber: Pribadi, 2019)

Pada Kollektiv Hotel penggunaan materiala alami yang menggambarkan desain rustik. Desain interior rustik modern akan membuat pengguna ruang merasa seperti kembali ke pedesaan namun dengan pemikiran masa kini. Gaya rustik mengutamakan perancangan suasna ruang agar terasa hangat dan nyaman. Karena pada dasarnya, gaya rustik berawal dari rumah log kayu yang dibangun di daerah iklim kutub. Demi menghangatnkan diri, maka digunakan material yang sesuai dan compatible seperti logwood yang disusun di semua elemen ruang. Warna-warna yang digunakan pada ruang rustik adalah warna yang membuat kesan hangat dan tenang digunakan memberikan kesan alami dan membuat suasan menjadi hangat.

\subsubsection{Nature of The Space}

\section{- Prospect \& Refuge}

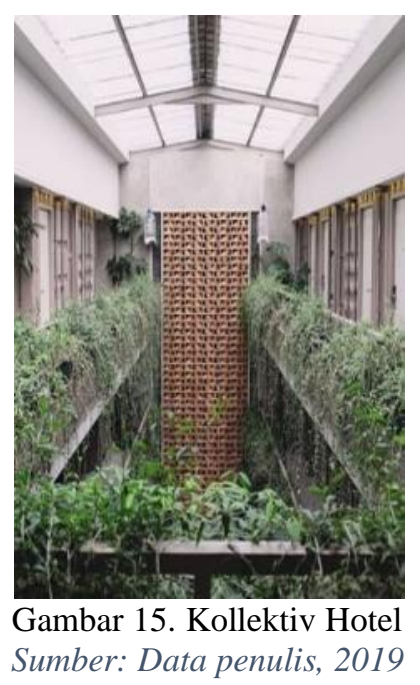

Penghijauan pada Kollektiv Hotel terdapat disetiap reling void yang berfungsi sebagai penghasil oksigen membuat kualitas di dalam hotel meningkat sehingga menimbulkan kesan sejuk. Selain itu, penghijauan dapat meminimalisir cahaya matahari. Selain itu, penghijauan dapat meminimalisir cahaya matahari dan meminimalisir angin yang masuk ke dalam ruangan. Vegetasi juga melindungi ruang interior dari polusi kebisingan dan debu dari lalu lintas tingkat jalanan.

- Mystery

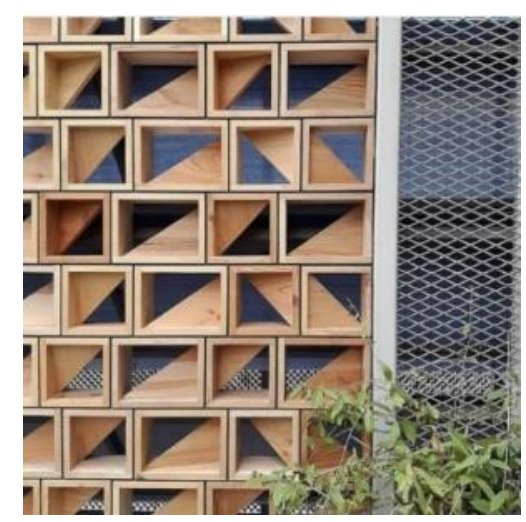

Gambar 16. Kollektiv Hotel

Sumber: Data penulis, 2019 
Dinding roster dibuat bukaan yang berpola sebagai tempat keluar masuknya udara maupun cahaya matahari, menyebabkan cahaya yang masuk menjadi lebih minim dan menimbulkan nilai estetik sehingga menyebabkan pengunjung yang datang memiliki rasa ingin tahu selanjutnya bergerak menelusuri ruangan lebih jauh.

\section{Kesimpulan}

Berdasar penelitian ini, dapat disimpulkan ahwa arsitektur biophilic merupakan konsep arsitektur yang berhubungan antar alam dengan psikologis penggunanya. Penerapan konsep biophilic diharap dapat menciptakan kondisi atau suasana dimana masyarakat tidak merasa stress serta mengurangi tingkat kesetresan seseorang.

Konsep biophilic dapat diterapkan dengan cara: membuat taman hijau atau perkarangan di halaman hunian, memperbanyak bukaan agar penghawaan dan pencahayaan alami, menanam tanaman di dalam ruang, penggunaan material alam (seperti: kayu dan batu ekspose).

Konsep arsitektur biophilic menjadi bangunan yang ramah lingkungan, oleh sebab itu, kesan ramah lingkungan tidak luput dari konsep green. Konsep green tidak bisa dilepaskan dari konsep keseluruhan sebagai green hospitality. Green Hospitality merupakan bangunan yang sebelum masuk ketahap rancangan, harus direncanakan secara matang dan dikomunikasikan dengan unsur manusia dan alam.

\section{Referensi}

Almusaed, Amjad. (2011). Biophilic and Bioclimatic Architecture Analitical Therapy for the Next Generation of Passive Sustainable Architecture (1 ed.). London: Springer- Verlag London. doi:10.1007/978-184996-534-7

Browning, W.D., Ryan, C.O., Clancy, J.O. (2014). 14 PATTERNS OF BIOPHILIC DESAIN IMPROVING HEALTY \& WELL-BEING IN THE BUILT ENVIRONMENT. New York NY | Washington DC: Terrapin Bright Green LLC.

Cahyawati, P. (2019). Perancangan Sekolah Alam di Kabupaten Malam dengan Pendekatan Arsitektur Biofilik. Surabaya: Universitas Islam Negeri Sunan Ampel .

Fahrurozi, I. (2019). Perpustakaan Umum dengan Ppendekatan Konsep Biofilik di Kabupaten Pekalongan. Surakarta: Universitas Muhammadiyah Surakarta.

Hadny, A. N. (2017). Penerapan Teori Biophilic Desain dalam Strategi Perancangan Sekolah Alam sebagai Saran Pendidikan Dasar di Karanganyar. Jurnal Ilmiah Arsitektur dan Lingkungan Binaan Vol 15, No 2.

Priatman, J. (2012). "Konsep Desain Biophilia" sebagai Dimensi Hijau pada Arsitektur Empatik. Seminar Nasional Menuju Arsitektur Berempati, pp 35-45.

Rahmasari, K. \&. (2017). Pendekatan Biophilic untuk Meningkatkan Kualitas Ruang pada Perkantoran Vertikal. Jurnal Sains \& Seni ITS Vol 6. No2, G60-G64.

Romadhani, I. S. (2017). Desain Ruang Relaksasi untuk Stress di Perkotaan dengan Penerapan Biophilic Design. JURNAL SAINS DAN SENI POMITS Vol 6, No 2, G104-g107.

Safitri, Z. (2017). Perancangan Pusat Kesehatan Kulit di Kota Malang dengan Pendekatan Arsitektur Biofilik. Malang: UIN Maulana Malik Ibrahim.

Yvonna S. Lincoln, Egon G. Guba. (1985). NATURALISTIC INQUIRY. London: SAGE Publications, Inc. 